\title{
Materials Consumption Decrease for Long-Span Prestressed Cable Roof
}

\author{
Arturs Stuklis ${ }^{1}$, Dmitrijs Serdjuks ${ }^{2}$, Vadims Goremikins ${ }^{3}$ \\ ${ }^{1}$ Riga Technical University, Department of Structural Engineering, \\ ${ }^{2}$ Riga Technical University, Department of Structural Engineering, \\ e-mail: Dmitrijs.Serdjuks@rtu.lv, \\ ${ }^{3}$ Czech Technical University in Prague, Department of Steel and Timber Structures, \\ e-mail:goremikins@gmail.com
}

\begin{abstract}
Limited raw materials and energy resources are actual national economy problems which can be solved by the decrease of weight, increase of span and durability of load bearing structures. The largest structural spans were achieved by application of cable structures. The roofs are one of the most widely used in practice type of cable structures. However, increased deformability and necessity of the special methods of stabilizing are significant cable roofs disadvantages. The prestressing of one or several groups of cables is one of the probable methods for stabilizing of cable roofs. According to the recommendations available in the literature, all cables of the roof must be prestressed by the equal forces. But after applying of design vertical load, values of the forces, acting in the cables of the roof, changes within the wide limits. So, using of structural materials will not be rational in this case, taking into account, that the cables cross-sections are constant because the cables cross-sections were determined basing on the maximum axial force, acting in the all cables.

Possibility to decrease materials consumption by the changing of prestressing forces for cables of the roof was checked on the example of saddle-shaped cable roof with the rigid support contour and dimensions $60 \times 60 \mathrm{~m}$ in the plan. Initial deflections of main suspension and stressing cables of the roof were equal to $7 \mathbf{m}$. Suspension and stressing cables of the net were placed with the step equal to $2.828 \mathrm{~m}$. Steel ropes with modulus of elasticity in 1.5.105 MPa were considered as a material of suspension and stressing cables of the roof. Suspension and stressing cables were divided into the groups, which are differed by the prestressing forces. Amount of cables groups changes within the limits from 1 to 27. Values of prestressing forces for cables groups change within the limits from 20 to $80 \%$ from the cables breaking force.

The dependences of material consumption and maximum vertical displacements of cable roof on the amount of cables groups and prestressing forces were determined as second power polynomial equations. It was stated, that division of suspension and stressing cables on the 18 groups enables to decrease cables material consumption by $19.2 \%$. Values of prestressing forces for suspension and stressing cables of the roof were equal to 57 and $80 \%$, from it load-carrying capacity, correspondingly.
\end{abstract}

Keywords: Cable net, prestressing force, saddle-shaped cable roof.

\section{INTRODUCTION}

Limited raw materials and energy resources are actual problems of national economy at the present moment. The decrease of weight, increase of span and durability of load carrying structures are possible ways to fix the problem. The increase of structural efficiency could be achieved by the choice of prestressed tensioned structures, where stress distribution by cross-section is close to uniform [1], [2]. High strength structural materials are used in the full scale in this case. Prestressed saddle-shaped cable roofs take a special position among the prestressed long span structures (Fig. 1) because the saddle shape and prestressing enable to provide stability of the roof surface during the action of alternating loads and to essentially decrease the ratio between applied load and structural dead weight (Fig. 1, c). The decreased ratio between applied load and structural dead weight save raw materials and energy resources [3], [4]. According to the recommendations available in the literature, all the cables of the load carrying net must be prestressed by the same force [5], [6].

But this recommendation is in the contradiction with the requirements to decrease structural materials consumption, because the difference between the axial forces, acting in the cables of the net after design vertical loads application, will be significant. Possibility to decrease structural materials consumption by $46 \%$ by the prestressing of each cable of the $30 \times 30 \mathrm{~m}$ in the plan saddle-shaped roof 
by the individual force was stated in the following investigations [3], [7]. But the considered cable roof was with the compliant contour, which is characterized by the increased displacements after application of design vertical load. Increased deformability is the main disadvantage of saddleshaped cable roofs with compliant contour, which decrease the area of it application by the temporary buildings mainly. This disadvantage can be improved by using of the rigid contour [8], [9]. Amount of the cables groups in the net, which are differed by the level of prestressing and the level of prestressing of cables in the each group are the main parameters, of cables net prestressing. So, possibility to decrease materials consumption of saddle-shaped cable roof with the rigid contour by the prestressing of the cables by the different forces must be checked.
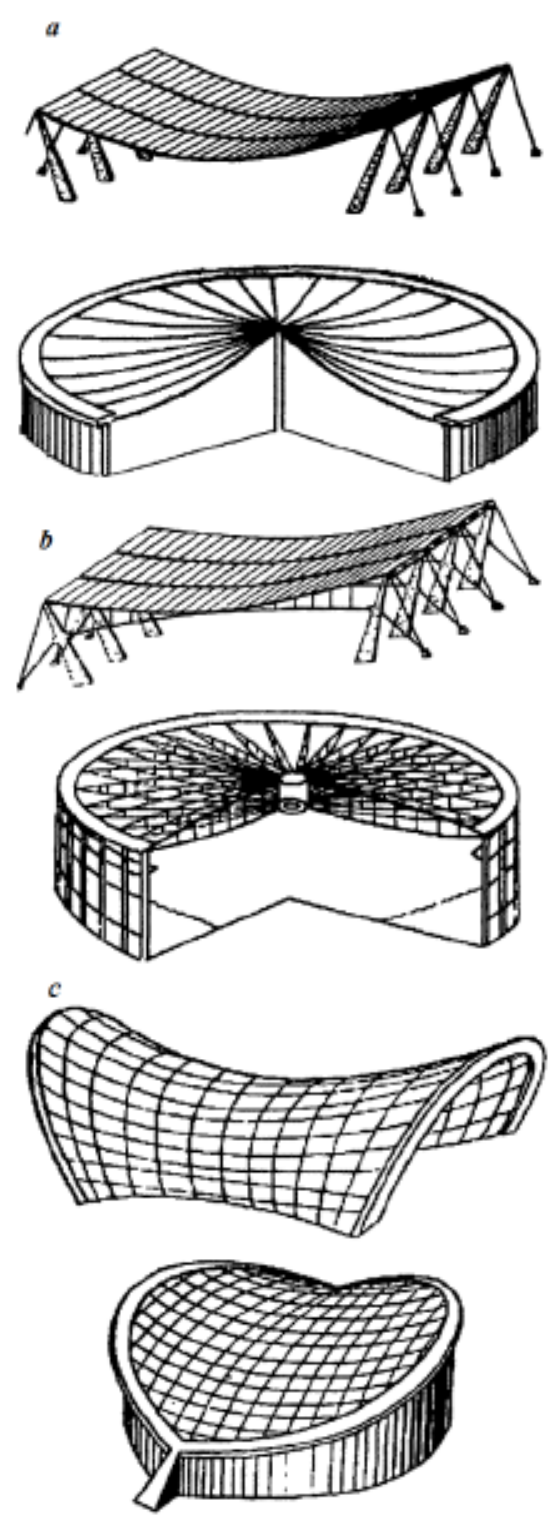
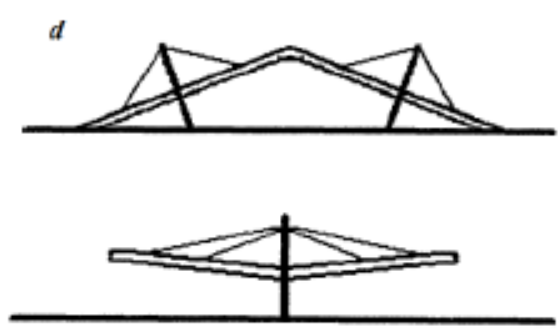

Fig. 1. Prestressed long-span cable structures: $a$ - one-chord roofs, $b$ - two-chord roofs, $c$ - saddle-shaped roofs, $d$-combined roofs (Truschev, 1983; Ermolov, 1991).

Possibility to obtain a cable net, where stresses, acting in the all cables are the same also should be considered. Rational amount of the cables groups in the net, which are differed by the level of prestressing and the level of prestressing of cables in the each group, should be evaluated also.

\section{APPROACH TO THE SOLUTION OF THE PROBLEM}

\section{A. Structural solution of long-span prestressed cable roof}

Prestressed saddle-shaped cable roof $60 \times 60 \mathrm{~m}$ in plan was considered as an object of investigation. The initial deflections of catenary and stressing cables were equal to 7 and $5 \mathrm{~m}$, correspondingly [5], [6]. So, the height of the prestressed saddle-shaped cable roof was equal to $12 \mathrm{~m}$. The distance between the catenary and stressing cables in the plan was equal to $2.828 \mathrm{~m}$. The span of main catenary and stressing diagonal cables was equal to $84.85 \mathrm{~m}$ (Fig. 2).

Supporting contour of the cable net was considered as a rigid one. The roofing consists from the two layers of timber boards, which were joined together by the nails, layer of heat insolation and layer of hydro insolation. Thickness of each layer of timber is equal to $33 \mathrm{~mm}$ and it strength class is C24. The two layers of timber boards can be created from the crosslaminated timber (CLT) panels, which must be placed so as the fiber direction of outer layers is parallel to the elements of supporting contour. The heat insulation is presented by the mineral wool PAROC ROS 30 with density equal to $100 \mathrm{~kg} / \mathrm{m}^{3}$ and thickness in $150 \mathrm{~mm}$. The hydro insolation is presented by the three layers of prepared roofing paper with the surface density in $0.15 \mathrm{kPa}$.

Steel cables with an elastic modulus of $1.5 \cdot 10^{5}$ $\mathrm{MPa}$ and ultimate tensile strength of steel wire of $1770 \mathrm{MPa}$ [10], were assumed as a material for the catenary and stressing cables. 

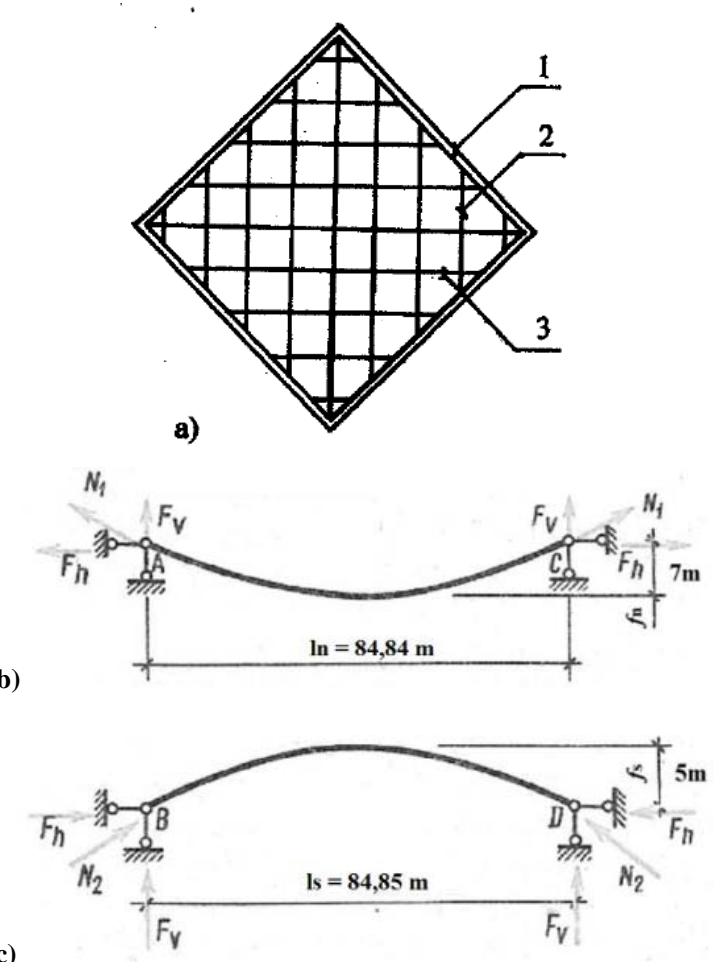

Fig. 2. Scheme of cable net for roof with rigid supporting contour a) and main diagonal catenary b) and stressing c) cables with support reactions: 1 - supporting contour, 2 - catenary cables, 3 stressing cables, $l_{s}$ and $l_{n}$ spans of main suspension and stressing cables, $f_{s}$ and $f_{n}$ - initial deflections of suspension and stressing cables, $F_{v}$ and $F_{h}-$ vertical and horizontal support reactions, $N_{l}$ and $N_{2}$ - maximum axial forces in suspension and stressing cables of the net.

\section{B. Method of analysis}

Possibility to decrease cable net's materials consumption for saddle-shaped cable roof with the rigid contour by the prestressing of the cables by the different forces is the major task of this paper. Possibility to obtain a cables net with decreased difference between the stresses, acting in the all cables [3], is considered as a condition, which must be satisfied to fix the problem.

Three variants of cable net with the different amount of cables groups with the different prestressing force were considered. The variants contain from 1 to 27 groups of cables. The level of cables prestressing changes within the limits from 20 to $80 \%$ from its load-carrying capacity.

Maximum axial forces, acting in catenary and stressing cables, were determined for the different stages of cable net loading. Maximum axial forces, acting in catenary cables were determined when the cable net is loaded by the dead weight and snow loads [11] in combination with prestressing. Maximum axial forces, acting in stressing cables and maximum vertical displacements of the cable net's nodes were determined by the ANSYS program for the stage, when cable net was loaded by the prestressing only.
Scheme of the cable net, which was created for it analysis by the ANSYS program, is shown in Figure 3. Design vertical load is applied as a point wise force to the nodes of the cable net.

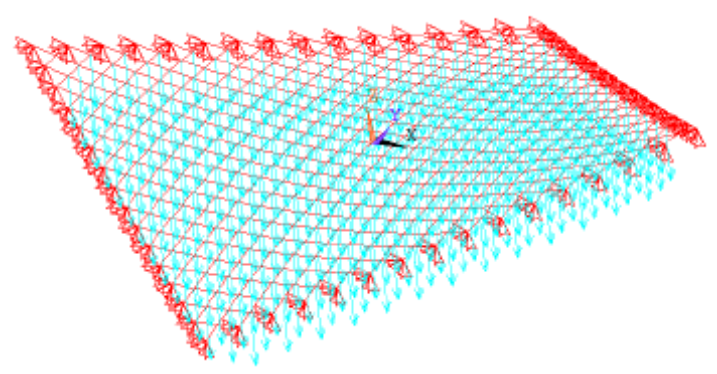

Fig. 3. Scheme of cable net loading.

Metallic cross-sections of catenary and stressing cables were determined by the following equation [12]:

$$
A_{m, n(s)} \geq 1.5 \cdot{\frac{n_{n,(s)} \cdot \gamma_{R}}{f_{u k}}}^{,}
$$

where $A_{m, n,(s)}$ - metallic cross-section of catenary and stressing cables;

$n_{n,(s)}$ - maximum axial forces, acting in catenary and stressing cables;

$\gamma_{\mathrm{R}}$ - partial factors;

$f_{u k}-$ characteristic value of tensile strength of steel wire.

Ultimate limit state (ULS) and serviceability limit state (SLS) were taken in to account during determination of cable's cross-sections and comparison of three mentioned variants of cable net prestressing.

Rational parameters of the cable net prestressing also must be evaluated in the work. Amount of the cables groups, which are differed by the level of prestressing $(n)$, prestressing levels of catenary $\left(N_{0, n}\right)$ and stressing $\left(N_{0, s}\right)$ cables were considered as the main parameters of the cable net prestressing.

The dependences of cable net materials' consumption $(G)$, coefficient of effectiveness of cable net materials using $(\psi)$, maximum vertical displacements of the cable net $\left(\delta_{\max }\right)$ on the main parameters of the cable net prestressing were determined. Each from the mentioned above main parameters of the cable net prestressing has three values: maximum, minimum and mean. It means, that the total number of treated variants was equal to 27 . The dependences were obtained as a second power polynomial equations on the base of numerical experiment, which was carried out using the software ANSYS. 


$$
\begin{aligned}
& G=b_{0}+b_{1} \cdot n+b_{2} \cdot N_{0, n}+b_{3} \cdot N_{0, s}+ \\
& +b_{12} \cdot n \cdot N_{0, n}+b_{13} \cdot n \cdot N_{0, s}+b_{23} \cdot N_{0, n} \cdot N_{0, s}+ \\
& +b_{11} \cdot n^{2}+b_{22} \cdot N_{0, n}{ }^{2}+b_{33} \cdot N_{0, s}{ }^{2},
\end{aligned}
$$

where $G$ - cable net materials' consumption; $n$ - amount of the cables groups, which are differed by the level of prestressing;

$N_{0, n}$ - prestressing level of catenary cables;

$N_{0, s}-$ prestressing level of stressing cables.

Rational from the point of view of materials consumption amount of the cables groups, which are differed by the level of prestressing, prestressing levels of catenary and stressing were determined by the systems of equations, which were analogous to the system (3), which was written for cable net materials consumption $(G)$.

$$
\left\{\begin{array}{l}
\frac{\partial G}{\partial n}=b_{1}+b_{12} \cdot N_{0, n}+b_{13} \cdot N_{0, s}+2 \cdot \mathrm{b}_{11} \cdot n=0, \\
\frac{\partial G}{\partial N_{0, n}}=b_{2}+b_{12} \cdot n+b_{23} \cdot N_{0, s}+2 \cdot b_{22} \cdot N_{0, n}=0, \\
\frac{\partial G}{\partial N_{0, s}}=b_{3}+b_{13} \cdot n+b_{23} \cdot N_{0, n}+2 \cdot b_{33} \cdot N_{0, s}=0,
\end{array} .\right.
$$

The obtained results then were analysed and corrected by the inspection.

\section{MATERIALS CONSUMPTION DECREASE FOR LONG-SPAN PRESTRESSED CABLE ROOF}

Design value of dead weight of the roofings was equal to $1.239 \mathrm{kPa}$. Snow load was determined for Riga climatical conditions. The snow load is considered as uniformly distributed by the horizontal projection of the roof. Design value of snow load was equal to $1.80 \mathrm{kPa}$. So the value of pointwise forces applied to the nodes of the cable net was equal to $24.31 \mathrm{kN}$.

The tension stresses distribution in the cables of the net for the variant with the four cables groups, which are differed by the prestressing level, is shown in Figure 4 . The values of tension stress changes within the limits from 535.83 to $1470 \mathrm{MPa}$. The values of tension stresses for variants with one and twenty seven groups of cables changes within the limits from 242.5 to $1129.6 \mathrm{MPa}$ and from 104.9 to $1843.1 \mathrm{MPa}$, correspondingly.

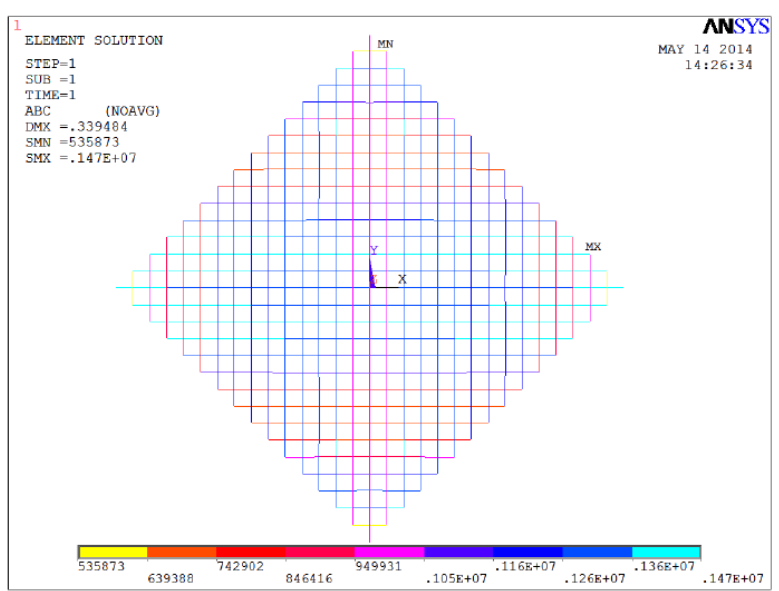

Fig. 4. Tension stresses distribution in the cables of the net for the variant with the four cables groups, which are differed by the prestressing level.

The dependence of cable net materials' consumption on the amount cables groups with the different prestressing force was obtained and shown in Figure 5.

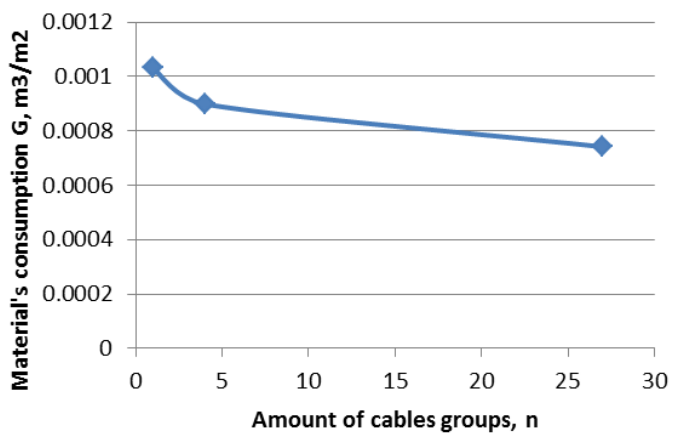

Fig. 5. The dependence of cable net materials' consumption on the amount cables groups with the different prestressing force.

It was stated, that materials volume was equal to $3.71,3.24$ and $2.67 \mathrm{~m}^{3}$ for the variants which contains 1,4 and 27 groups of cables, which are differed by the prestressing level, correspondingly. So, increase of cable groups amount with the different level of prestressing from 1 to 4 and 27 enables to decrease cable net materials consumption by 21.3 and $39.2 \%$, correspondingly.

\section{EVALUATION OF RATIONAL PARAMETERS OF CABLE NET PRESTRESSING}

The dependences of cable net materials' consumption (G) coefficient of effectiveness of cable net materials using $(\psi)$, maximum vertical displacements of the cable net $\left(\delta_{\max }\right)$ on the amount of cables groups $(n)$, which are differed by the levels of prestressing and this level for catenary $\left(N_{0, n}\right)$ and stressing $\left(N_{0, s}\right)$ cables, were determined basing on the 
results of numerical experiment, which was carried out using the software ANSYS. Stresses decrease (\%) in the cables of the net due to changing of groups amount which are differed by the level of prestressing is considered as the effectiveness of cable net materials using $(\psi)$. The variants contain 1,4 and 27 groups of cables. The levels of catenary and stressing cables prestressing were equal to 0,40 and $80 \%$ from it load-carrying capacity. The coefficients of second power polynomial equations for materials' consumption $(\mathrm{G})$ coefficient of effectiveness of cable net materials using $(\psi)$ and maximum vertical displacements of the cable net $\left(\delta_{\max }\right)$ are given in Table 1. The values of obtained coefficients allow to analyze level of influence of the amount of cable groups and prestressing level of catenary and stressing cables on the cable net materials' consumption, coefficient of effectiveness of cable net materials using, maximum vertical displacements of the cable net. The amount of cables groups is the factors which most significantly influence the mentioned parameters of the cable net. Influence of prestressing level of catenary and stressing cables is significant also, but their levels of importance were form 7.17 to 6.21 times less than the same for the amount of cables groups. Absolute value of corresponding coefficients $b_{1}, b_{2}$, and $b_{3}$ are considered as the levels of importance for amount of cables groups and prestressing level of catenary and stressing cables, correspondingly.

Rational from the point of view of materials consumption, effectiveness of cable net materials using and maximum vertical displacements of the cable net amount of the cables groups, prestressing levels of catenary and stressing cables of the net were determined by the system of equations (3) and analogous systems. Rational values of the cables groups, prestressing levels of catenary and stressing cables of the net changes within the limits from 14 to 18 and from 49.6 to $57.3 \%$, correspondingly.

TABLE 1

THE COEFFICIENTS OF SECOND POWER POLYNOMIAL EQUATIONS

\begin{tabular}{|l|l|l|l|}
\hline $\begin{array}{l}\text { Coefficients of second power } \\
\text { polynomial equations }\end{array}$ & $\begin{array}{l}\text { Dependence for materials' } \\
\text { consumption }(\mathrm{G})\end{array}$ & $\begin{array}{l}\text { Dependence for coefficient of } \\
\text { effectiveness of cable net } \\
\text { materials using }(\psi)\end{array}$ & $\begin{array}{l}\text { Dependence for maximum } \\
\text { vertical displacements of the } \\
\text { cable net }\left(\delta_{\max }\right)\end{array}$ \\
\hline$b_{0}$ & $1.08 \cdot 10^{-3}$ & 374.70 & 489.52 \\
\hline$b_{1}$ & $-5.14 \cdot 10^{-5}$ & 26.88 & 12.86 \\
\hline$b_{2}$ & 0 & -8.89 & -2.60 \\
\hline$b_{3}$ & 0 & -6.92 & 2.07 \\
\hline$b_{11}$ & $1.43 \cdot 10^{-6}$ & -1.24 & -0.36 \\
\hline$b_{12}$ & 0 & 0.11 & 0.01 \\
\hline$b_{13}$ & 0.07 & 0.03 \\
\hline$b_{22}$ & 0 & 0.04 & -0.02 \\
\hline$b_{23}$ & 0 & 0.06 & -0.02 \\
\hline$b_{33}$ & 0 & 0.03 & -0.01 \\
\hline
\end{tabular}

The dependences of the effectiveness of cable net materials using from the prestressing level of catenary and stressing cables of the net and the cable net materials consumption on the amount of cables groups are shown in Figure 6 and Figure 7. The dependence of the net prestressing level of the catenary and stressing cables on the maximal vertical deflection is shown on Figure 8.

The dependences which are shown on Figure 6 and Figure 8 were obtained for the amount of cables groups equal to 18 . The both dependences have nonlinear character. The dependences on Fig. 7 were obtained when the prestressing levels of catenary and stressing cables of the net were equal to $57 \%$ and $80 \%$ from its load-carrying capacity, correspondingly. This result was obtained by the method of inspection basing on the values, which are numerically obtained and indicated on the Figure 6 and Figure 8. Character of obtained dependence did not allow getting the maximum effectiveness of cable net materials using by the analytical approach only.

It was stated, that materials consumption for the cable net with 18 cables groups, prestressing levels of catenary and stressing cables of the net equal to $57 \%$ and $80 \%$, correspondingly, is equal to $6.22 \cdot 10^{4}$ $\mathrm{m}^{3} / \mathrm{m}^{2}$. So, materials consumption can be decreased by $16.17 \%$ in comparison with the variant of the net with 27 groups of cables, which are differed by it prestressing level.

The prestressing level of catenary cables should be maximal to obtain the minimum deflections. So, increase of levels of prestressing for catenary and stressing cables from 20 to $80 \%$ from its loadcarrying capacity enables to decrease the maximum vertical displacements from 600 till $200 \mathrm{~mm}$ for considered saddle-shaped cable roof with the rigid support contour and dimensions 60x60 $\mathrm{m}$ in the plan. 


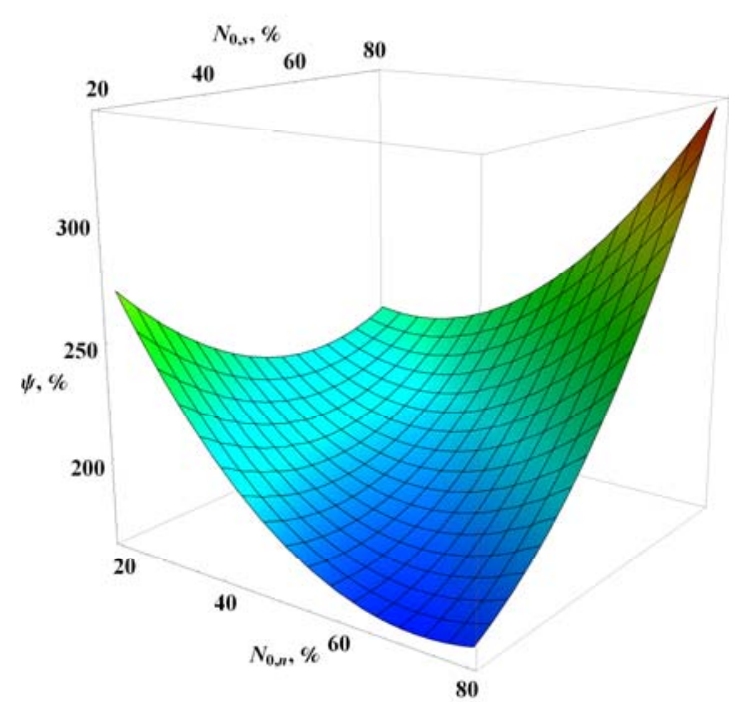

Fig. 6. The dependence of the effectiveness of cable net materials using from the prestressing level of catenary and stressing cables of the net.

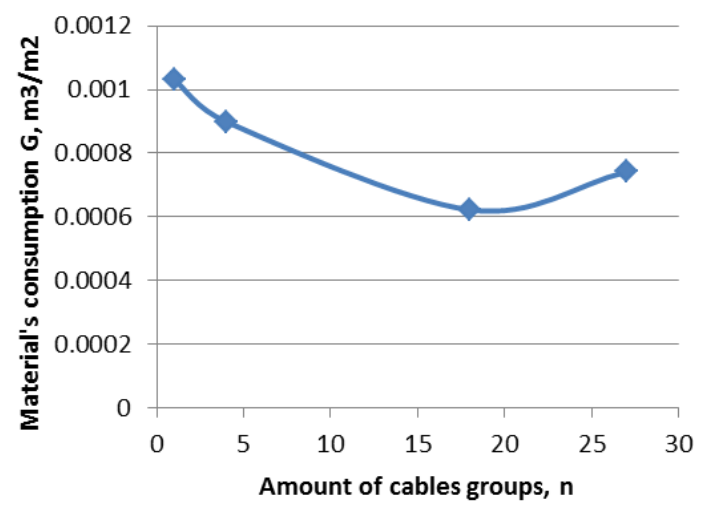

Fig. 7. The dependence of the cable net materials consumption on the amount of cables groups.

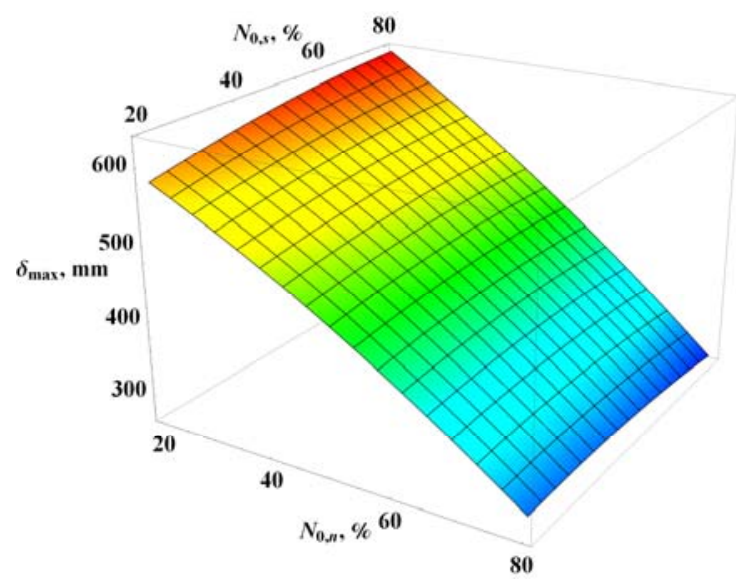

Fig. 8. The dependence of cable net prestressing level of catenary and stressing cables on maximal vertical deflection.

\section{CONCLUSIONS}

Possibility to decrease materials consumption by the changing of prestressing forces for cables of the roof was checked on the example of saddle-shaped cable roof with the rigid support contour and dimensions $60 \times 60 \mathrm{~m}$ in the plan. So, increase of cable groups amount with the different level of prestressing from 1 to 4 and 27, enables to decrease cable net materials consumption by 21.3 and $39.2 \%$, correspondingly. Values of prestressing forces, which were applied to the groups of cables, changes within the limits from 20 to $80 \%$ from the cables breaking force.

Rational from the point of view of cable net material's consumption amount of cables groups, which are differed by the levels of prestressing and prestressing level for catenary and stressing cables, were determined It was stated, that division of suspension and stressing cables on the 18 groups enables to decrease cables material consumption by $19.2 \%$. Values of prestressing forces for suspension and stressing cables of the roof were equal to 57 and $80 \%$, from it load-carrying capacity, correspondingly.

\section{ACKNOWLEDGEMENT}

The research leading to these results has received the funding from Latvia state research programme under grant agreement "Innovative Materials and Smart Technologies for Environmental Safety, IMATECH". Project Nr.3, PVS ID1854, Task Nr.3.

\section{REFERENCES}

[1] V. Goremikins, "Rational Large Span Prestressed Cable Structure," Doctoral Thesis, Riga Technical University, Riga, 2013.

[2] V. Goremikins, K. Rocens and D. Serdjuks, "Decreasing Displacements of Prestressed Suspension Bridge," Journal of Civil Engineering and Management vol. 18, no. 6, 2012, pp. 858-866.

[3] D. Serdjuks, K. Rocens, L. Pakrastins, "Prestress Losses in the Stabilizing Cables of a Composite Saddle-Shaped Cable Roof," Mechanics of Composite Materials, vol. 39, no. 4, 2003, pp. 341-346.

[4] V. Goremikins, K. Rocens, D. Serdjuks, "Cable Truss Analyses for Suspension Bridge," in Proc. of 10th International Scientific Conference "Engineering for Rural Development”, 24-25 May, 2012, Jelgava, Latvia, vol. 11, 2012, pp. 228-233.

[5] A. Trushev, Spatious steel Structures, Moscow, 1983.

[6] V. Ermolov, Engineering Structures. Moscow, 1991.

[7] D. Serdjuks, K. Rocens, "Decrease the Displacements of a Composite Saddle-Shaped Cable Roof," Mechanics of Composite Materials, vol. 40, no. 5, 2004, pp. 675-684.

[8] V. Mihailov, Predvariteljno naprjažennije kombinirovannije $i$ vantovije konstrukciji. Moskva: ACB, 2002.

[9] L. Pakrastinsh, K. Rocens, D. Serdjuks, "Deformability of Hierarchic Cable Roof," Journal of Constructional Steel Research, vol. 62, 2006, pp. 1295-1301.

[10] M. Lisicins, V. Lapkovskis, V. Mironovs, D. Serdjuks, "Composite Load-Bearing Element Based on the Perforated Steel Wastes," in Proc. of 4th International Conference Advanced Construction, 9-10 October, 2014, Kaunas, Lithuania, 2014, pp. 158-163. 
Arturs Stuklis, et al./ Environment. Technology. Resources, (2015), Volume I, 209-215

[11] European Committee for Standartization, Eurocode 1: Actions on buildings, Brussels, 2004.
[12] European Committee for Standartization, Eurocode 3: Design of steel structures - Part 1.11: Design of structures with tensile components, Brussels, 2003. 